\title{
A Note on Names and Book Titles
}

The chapters collected in this volume refer to a large number of jurists from the sixteenth to eighteenth centuries. As was the convention of the early modern period, many of these jurists were known by the Latinised versions of their names and surnames in addition to their names and surnames in the vernacular languages of early modern Europe. To assist the reader in traversing this issue, every effort has been made to verify both the vernacular and Latinised versions of the names of jurists using the library catalogues of the British Library. Similarly, for book titles in Latin and their editions, the Universal Short Title Catalogue has been used to verify titles and editions. We have not attempted to standardise names across the volume as to do so would interfere too much with the individual chapters. Instead, we have provided guidance throughout where names might create confusion. This volume, like the others in this series, follows the citation style of the Edinburgh Law Review. Since this style of citation is somewhat minimalist, especially in relation to bibliographic information regarding publisher and place of publication of books, this information has been retained in the text and in footnotes in relation to books from the early modern period where such information is central to the point being made. 